\section{University of New Hampshire}

Carsey School of Public Policy

\section{CARSEY RESEARCH}

National Issue Brief \#110

Fall 2016

\title{
White Deaths Exceed Births in One-Third of U.S. States
}

Rogelio Sáenz and Kenneth M. Johnson

I n 2014, deaths among non-Hispanic whites exceeded births in more states than at any time in U.S. history. Seventeen states, home to 121 million residents or roughly 38 percent of the U.S. population, had more deaths than births among non-Hispanic whites (hereafter referred to as whites) in 2014, compared to just four in 2004. When births fail to keep pace with deaths, a region is said to have a "natural decrease" in population, which can only be offset by migration gains. In twelve of the seventeen states with white natural decreases, the white population diminished overall between 2013 and 2014 .

This research is the first to examine the growing incidence of white natural decrease among U.S. states and to consider its policy implications. Our analysis of the demographic factors that cause white natural decrease suggests that the pace is likely to pick up in the future.

Over the last several decades, demographers have noted the growing incidence of natural decrease in the United States. ${ }^{1}$ More widespread natural decrease results from declining fertility due to the Great Recession, and the aging of the large baby boom cohorts born between 1946 and 1964. This senior population is projected to expand from nearly 15 percent of the total population in 2015 to nearly 24 percent in $2060 .^{2}$ Much of this aging baby boom population is white, and so white mortality is growing. Together, growing white mortality and the diminishing number of white births increase the likelihood of more white natural decrease. In contrast, births exceed deaths by a considerable margin among the younger Latino population, and the combination of these very different demographic trends is increasing the diversity of the U.S. population. ${ }^{3}$

Though demographers have documented the growing incidence of natural decrease among the overall population in U.S. counties, little attention has been given to its occurrence among racial sub-groups at any level of geography. To address this gap, we use data

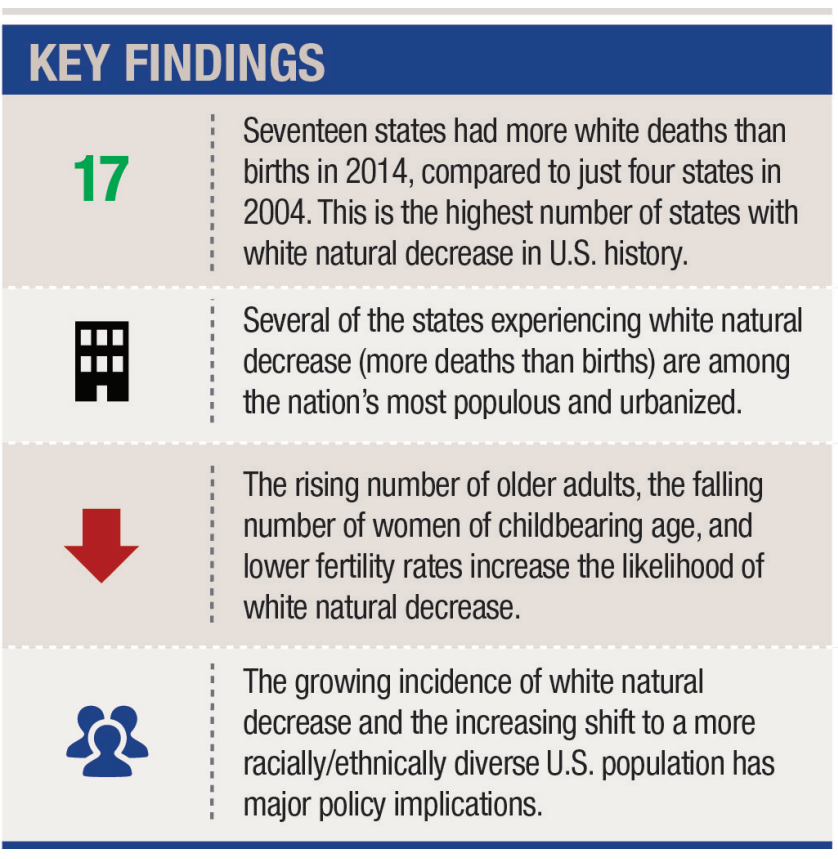

from the National Center for Health Statistics of the Centers for Disease Control to examine the annual volume of births and deaths among whites from 1999 to 2014 for each state. ${ }^{4}$ We focus on whites because they represent the largest share of the U.S. population and because their demographic profile increases the likelihood of natural decrease. We find a significant rise in the number of states experiencing white natural decrease in the last few years. The comparison of these states to others where white births exceed deaths helps us to understand what combination of demographic changes produce natural decrease. Though white natural decrease is clearly on the rise, only two states have more deaths than births in their total populations. This low incidence of overall natural decrease in U.S. states reflects the growing importance of Latino natural increase to overall U.S. demographic trends. 


\section{Fewer White Births and More White Deaths}

Between 1999 and 2014, the number of white births fell by 8.4 percent to 2,150,000 and the number of white deaths rose by 5.8 percent to 2,066,000. Both these demographic changes contributed to waning levels of natural increase (Figure 1). The pace of decline in white births intensified from 2007 to 2013 , due in part to the Great Recession's significant impact on U.S. fertility. ${ }^{5}$ The recession, the greatest shock to the American economic system in nearly two generations, influenced both fertility and life-cycle decisions for many families.

With significantly fewer white births and a rising number of deaths, natural increase (births minus deaths) plummeted from 393,000 in 1999 to just 82,000 in 2014, a decline of 79 percent. Though the rising volume of deaths (an increase of nearly $114,000)$ contributed significantly to this dwindling natural increase, it was the diminishing number of births (a decline of 197,000) that accounted for most of the reduction in natural increase.

Demographers often use the birth-to-death ratio (BDR) to track the changing relationship between fertility and mortality in a population. For whites, the BDR fell from 1.20 in 1999 to just 1.04 in 2014 (Figure 2). Thus, the number of white births for each white death declined from 1.20 to 1.04 .

\section{FIGURE 1. BIRTHS AND DEATHS AMONG WHITES, 1999-2014}

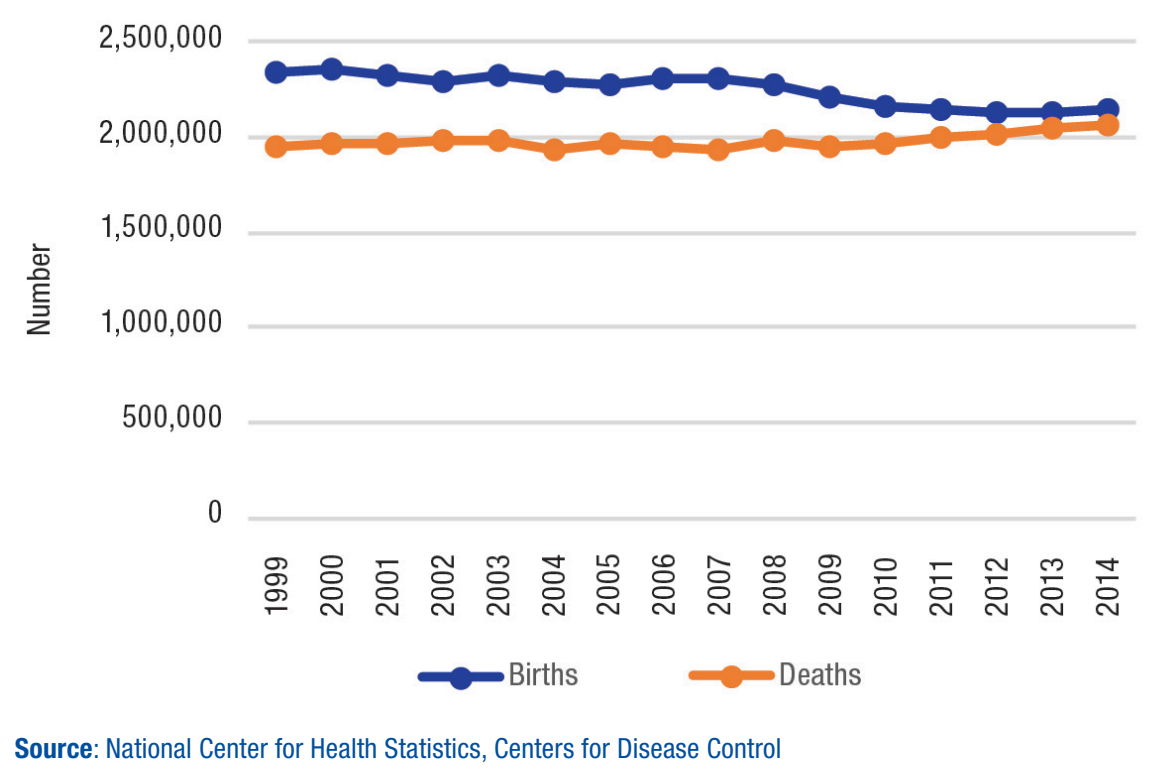

FIGURE 2. BIRTH-TO-DEATH RATIO AMONG WHITES, 1999-2014

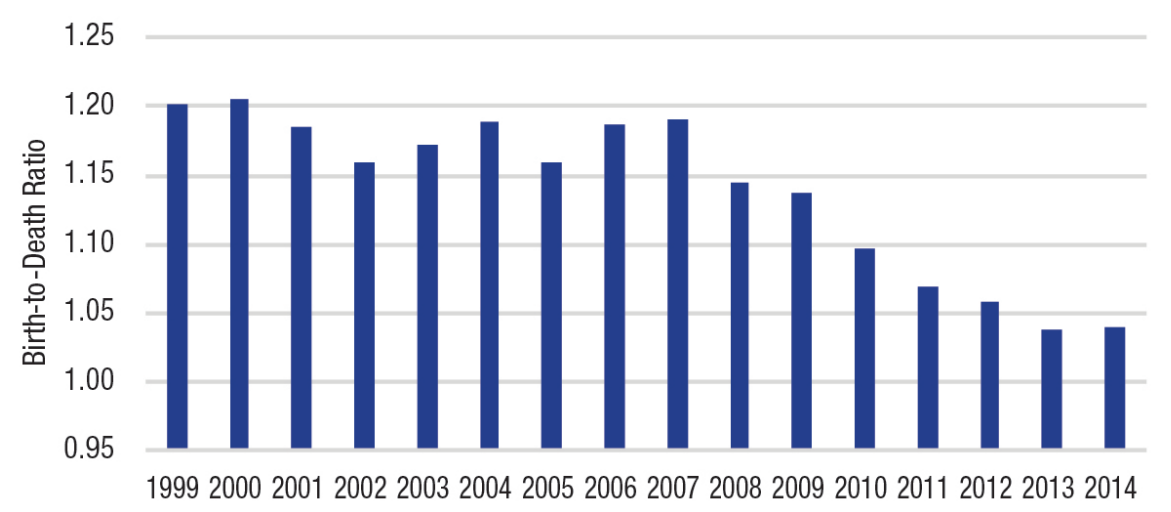

Source: National Center for Health Statistics, Centers for Disease Control

\section{Increasing Incidence of States With More White Deaths Than Births}

While national data reflect a significant reduction in natural increase among whites between 1999 and 2014, the onset of natural decrease has only occurred recently in many states. In 1999, four states had white natural decrease; by 2014 seventeen states did. The steepest rise occurred after 2006, when the Great Recession began to exert a substantial impact on fertility (Figure 3).

Several states have experienced protracted white natural decrease. It has been occurring for more than a decade in Florida, Pennsylvania, Rhode Island, West Virginia, California, and New Mexico. Past research on natural 
FIGURE 3. STATES WITH MORE DEATHS THAN BIRTHS AMONG WHITE POPULATION, 1999-2014

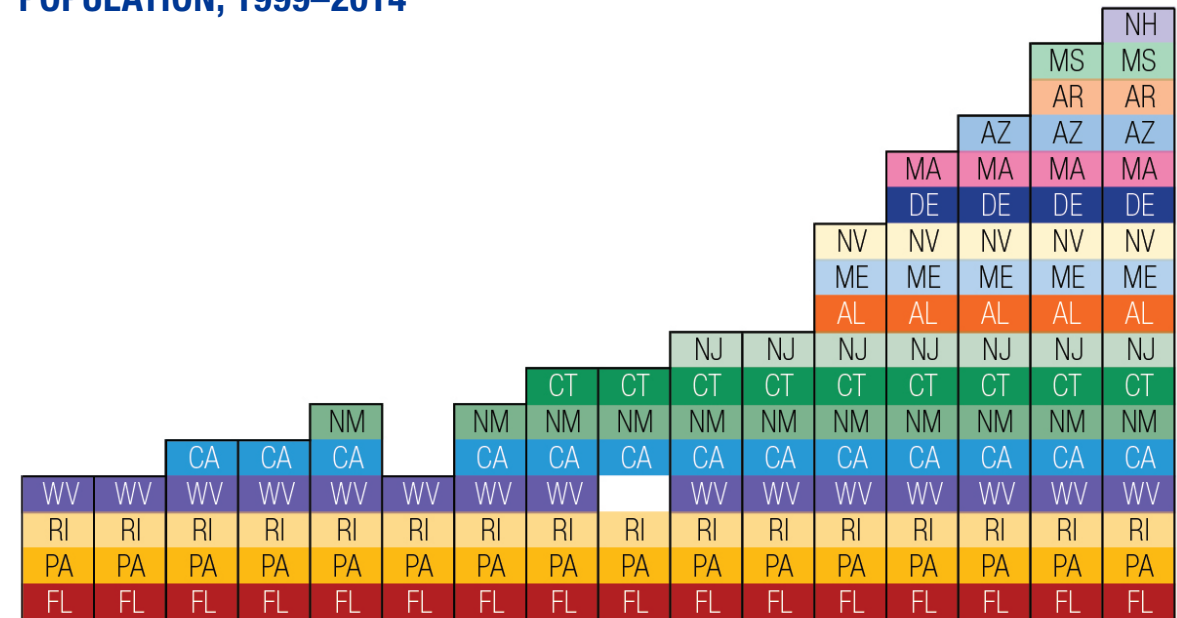

1999200020012002200320042005200620072008200920102011201220132014

Source: Authors' compilation of data from National Center for Health Statistic, Centers for Disease Control

decrease in U.S. counties noted that it was occurring mostly in rural areas. ${ }^{6}$ In contrast, state-level white natural decrease is occurring in populous states such as California, Florida, Pennsylvania, New Jersey, Arizona, and Massachusetts, which have diverse economies and numerous metropolitan areas.

A finding from previous research on natural decrease, which is consistent with our findings, is that once an area begins to experience natural decrease, the trend is likely to continue. ${ }^{7}$ Only California, New Mexico, and West Virginia have experienced natural increase after the initial onset of decrease (Figure 3 ), and in each case it was only for a year. This pattern suggests a high likelihood of future natural decrease among these seventeen states. More states are likely to begin to have white natural decrease in the near future. Vermont and South Carolina have each sustained a significant drop in white natural increase over the past five years-from 598 in 2010 to just 182 in 2014 in Vermont, and from 3,120 in 2010 to 339 in 2014 in South Carolina. Tennessee and Oregon have also recently experienced precipitous declines in white natural increase.

\section{Geographic Distribution of States by Level of Natural Change}

There is considerable spatial variation in the level of white natural increase or decrease among the states. Figure 4 divides the fifty states and the District of Columbia into three categories based on their white birth-to-death ratios in 2014: the seventeen natural-decrease states (BDR less than 1 , reflecting fewer births than deaths); the fifteen states where births modestly exceeded deaths (BDR between 1.00 and 1.14); and the nineteen high natural-increase states (BDR of 1.15 or higher).
White natural decrease states are widely dispersed, with clusters in the South, West, and Northeast regions. States with minimal white natural increase are also widely distributed, though they are often in close proximity to the naturaldecrease states. States with high natural increase are concentrated in the Mountain West and the West North Central regions but also include Texas, Louisiana, Indiana, and Virginia.

\section{More Older Adults,} Fewer Mothers, and Low
Fertility Drive White
Natural Decrease

Powerful demographic forces have combined to raise the incidence of white natural decrease. Here we consider four demographic factors that have been identified as important in accounting for natural decrease in both the United States and Europe. ${ }^{8}$

First, the percentage of the white population that is 65 and older in 2014 reflects the age structure of the state. ${ }^{9}$ Generally, an older population increases the likelihood of natural decrease due to an increase in deaths. Second, the percentage of white women 15 and older who are in their childbearing years (15-44) in 2014 signifies the relative share of women who are capable of giving birth. ${ }^{10} \mathrm{~A}$ larger proportion of women in their childbearing years is likely to increase the number of births. Third, the white total fertility rate in 2014 represents the average number of births per woman in the state. ${ }^{11}$ High fertility rates diminish the likelihood of natural decrease 


\section{FIGURE 4. STATES BY INCIDENCE OF WHITE NATURAL INCREASE OR DECREASE, 2014}

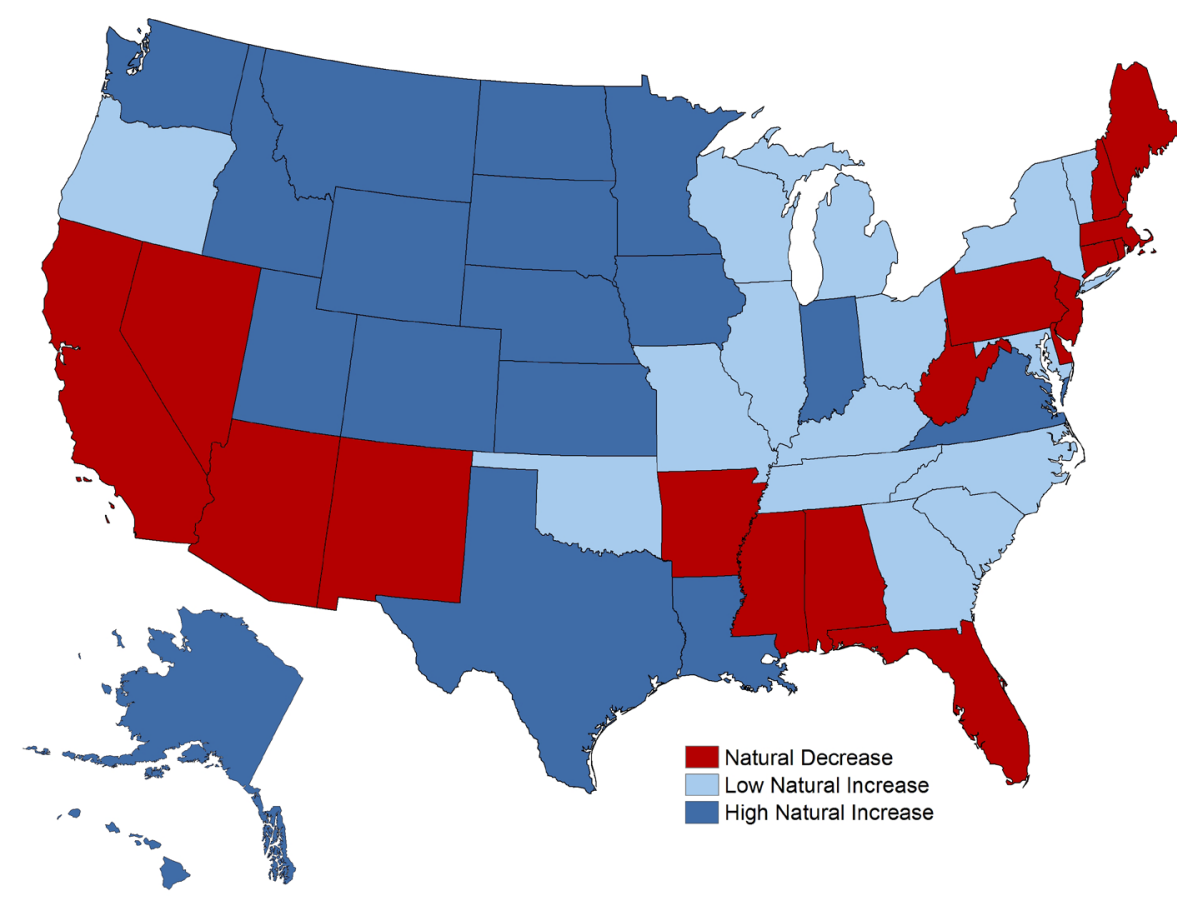

Source: National Center for Health Statistics, Centers for Disease Control

by increasing the number of births. Fourth, the percentage of white females less than 15 years of age represents the relative availability of cohorts who will enter their childbearing years in the near future. ${ }^{12}$ This reflects the potential of the next generation of women to produce future children. For each of these demographic variables, we divided states into those that rank in the low, moderate, and high category based on the state's value compared to other states.

The narrowing gap between white births and deaths reflects the influence of the first three of these demographic forces. As expected, the likelihood of white natural decrease is greatest in states with a large concentration of older whites (Figure 5A). The white population is aging rapidly, as reflected in a rise in median age for whites from 39 in 2000 to 43 in 2014. During the same period, the percentage of persons 65 and older increased from 15 percent of the white population in 2000 to 18 percent in 2014. Because older populations face higher mortality risks, population aging increases the number of white deaths. Nearly 71 percent of the natural-decrease states had a high percentage of their populations in the 65 -and-over category, compared to none of the states with a relatively high white birth-to-death ratio.

Another important factor is the proportional share of white women of childbearing age. Previous research suggests that natural decrease is more likely when there are fewer women of childbearing age. Overall, the number of white women of childbearing age (15-44) declined by 4.7 million between 2000 and 2014, or nearly 12 percent. Approximately 71 percent of the natural-decrease states had relatively few white women of childbearing age (Figure 5B). In contrast, nearly 74 percent of the high natural-increase states had a high percentage of women of childbearing age.

White natural decrease is also more common in states that have low white fertility rates. Nearly 65 percent of the natural-decrease states are in the lowest fertility category, compared to just 16 percent of the states with high levels of natural increase (Figure 5C). However, the differences here are less pronounced than those for the proportion over 65 and for the proportion of women in their childbearing years. Some naturaldecrease states have moderate or relatively high fertility levels.

The demographic factors examined so far help to explain why some states currently have white natural decrease and others do not. The percent of the female population less than 15 years old gives us a glimpse of the future. States with smaller proportions of white females under 15 have less potential for future white births than states with larger portions of young females. Most natural-decrease states have relatively small cohorts of young white females, thus the risk of continued natural decrease is high for them (Figure 5D). In contrast, states that currently have a large excess of white births over deaths also have a larger percentage of young white females able to produce the next generation.

In sum, the likelihood of white natural decrease is greatest in states 


\section{FIGURE 5. PERCENTAGE DISTRIBUTION OF STATES BY LEVEL OF NATURAL CHANGE ASSOCIATED WITH FOUR EXPLANATORY FACTORS AMONG WHITES, 2014}

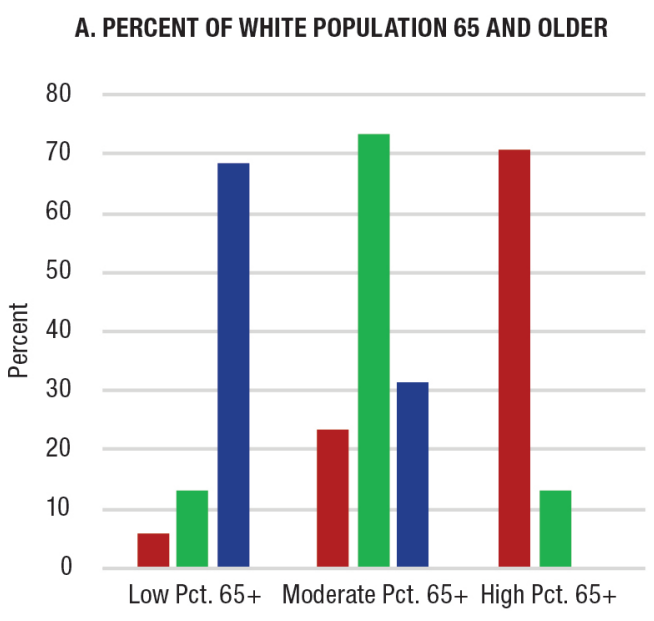

Natural Decline $\square$ Low Natural Increase $\square$ High Natural Increase

\section{TOTAL FERTILITY RATE (TFR) FOR WHITES}

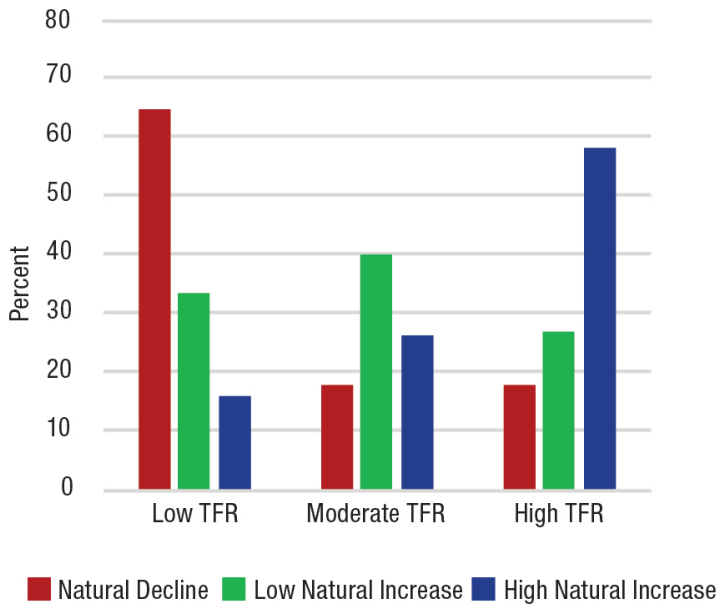

B. PERCENT OF WHITE WOMEN 15 AND OLDER IN CHILDBEARING AGES (15-44)

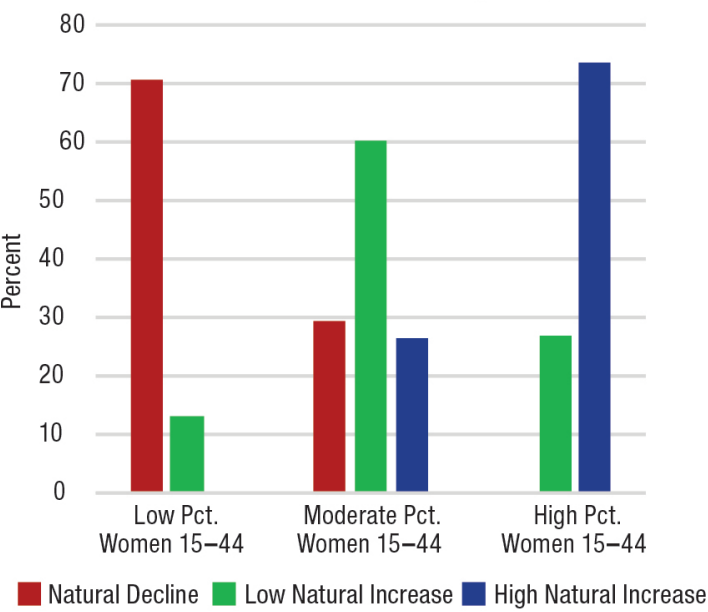

D. PERCENT OF WHITE FEMALE POPULATION LESS THAN 15 YEARS OF AGE

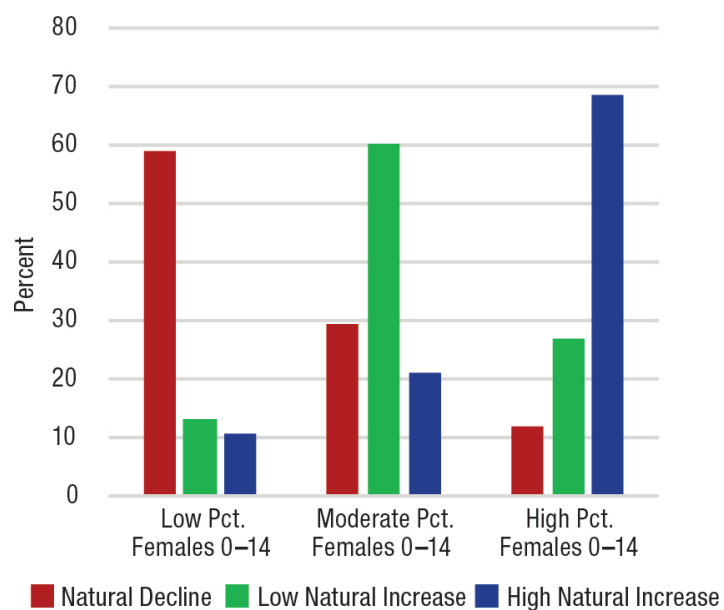

Source: National Center for Health Statistics, Centers for Disease Control; U.S. Census Bureau population estimates; and American Community Survey public-use file.

that have a larger proportion of older adults, a smaller proportion of women of childbearing age, and a lower fertility rate.

\section{Few States Have Natural Decline in Total Population}

Though one-third of U.S. states had more white deaths than white births in 2014, only two statesWest Virginia and Maine-had more deaths than births in their overall populations. West Virginia has had natural decrease in its total population in twelve of the last sixteen years; Maine has experienced it in each of the last four years (2011-2014). The other fifteen states with white natural decrease are still experiencing overall natural increase because other racial/ ethnic populations, especially Latinos, produced a great enough surplus of births over deaths to offset the white natural decrease.
The Latino population is considerably younger (median age of 28.4 in 2014) and has higher fertility rates than the white population, and so Latino births exceeded deaths by a substantial margin in all fifty states and the District of Columbia in 2014. In twelve of the seventeen states with more white deaths than births in 2014, Latino natural increase alone was sufficient to offset the natural decline of whites. In California, for example, the Latino natural 
increase of 193,311 was far greater than the 13,168 natural decrease of whites. However, in the other five states, the natural decline of whites was greater than the Latino natural increase. In Florida, for example, the Latino natural increase was 39,768 , compared to a natural decrease of 40,565 among whites. Gains among other minorities in Florida supplemented the Latino gain to produce an overall natural increase. In Maine and West Virginia, the two states with overall natural decline, there were few Latinos or members of other minority groups to offset the white natural decrease.

\section{Conclusion}

Our research, the first to examine white natural decrease at the state level, finds that seventeen states are experiencing it currently and that its occurrence has increased substantially over the past decade. We also find that several of the states experiencing white natural decline are among the nation's most populous and urbanized. Here our findings differ from prior county-level research that has suggested that overall natural decrease tends to be concentrated in rural areas of the Great Plains. ${ }^{13}$

A policy issue with significant implications for white natural decrease is the increasing rate of mortality among working-class whites from drug and alcohol abuse and suicide. ${ }^{14}$ Drug-induced deaths (including intentional suicide deaths and accidental drug overdose deaths) outnumbered motor vehicle accident deaths among whites in forty-one states in 2014 compared to ten states in $2004 .{ }^{15}$ All but two of the seventeen states where white deaths exceeded births had more drug-induced deaths than motor vehicle accident deaths in 2014 . Such drug-related overdose deaths are likely to speed the transition from natural increase to natural decrease in some states.

The growing natural decline among whites in U.S. states contributes to the larger racial/ethnic shifts occurring in the U.S. population. As white natural increase has diminished, the share of the U.S. population that is white has declined from 79.6 percent in 1980 to 61.9 percent in 2014. Census Bureau projections suggest that the white population will begin to decline in absolute numbers between 2030 and 2040, and that by 2050 whites will constitute less than half ( 47 percent) of the U.S. population. ${ }^{16}$

In contrast, the youthful Latino population has increased significantly over the last three decades. It is responsible for the majority of all U.S. population increase and is expected to contribute even more in the future. ${ }^{17}$ The share of the nation's population that is Latino rose from 6.4 percent in 1980 to 17.3 percent in 2014, and it is projected to reach 29 percent by $2060 .{ }^{18}$

As we have seen, Latino natural increase has been a significant contributor to overall U.S. natural increase over the past several decades. However, it diminished with the onset of the Great Recession, declining from 927,000 in 2007 to 745,000 in 2014. Factors contributing to this decline include a significant drop in immigration from Mexico ${ }^{19}$ and a substantial reduction in births. ${ }^{20}$ Latina births fell by 14 percent between 2007 and 2014, twice as great as the decline in white births (7 percent) ${ }^{21}$ Further reductions in fertility as well as reduced immigration for Latinos could make it less likely that Latino natural increase will be sufficient to offset white natural decline in some states.

The demographic trends underlying the current natural decline of whites and the increasing shift to a more racially/ethnically diverse U.S. population have major policy implications. First, the largely white older population will grow rapidly as baby boom cohorts continue to age. As they do, demands on the health care and retirement system will dramatically increase. Second, the youthful population-increasingly a population of color-will require major investments in education and training if the United States is to maintain a productive workforce in an increasingly competitive technological and global labor market. With an aging white population and a youthful population increasingly of color, each with competing demands on government budgets, there is considerable potential for conflicts concerning funding priorities. However, these new generations of color also provide a potential demographic lifeline to America's aging white population by reinvigorating local commerce and labor markets and by fostering economic development that will contribute to meeting the growing demands on the nation's health care and retirement programs. ${ }^{22}$

Natural decrease is the ultimate demographic consequence of population aging, low fertility, and a diminishing proportion of the childbearing-age population. The rapid rise in the number of U.S. states experiencing white natural decrease reflects the demographic changes underway. Our analysis suggests that more states are likely to experience white natural decrease in the near future. However, there is a low probability of natural decrease 
in the overall population in most states in the foreseeable future due to the substantial natural increase among Latinos, African Americans, Asians, and native peoples.

Many developed nations already face far more widespread natural decrease than the United States. ${ }^{23}$ In Europe, overall deaths exceed births in seventeen countries. ${ }^{24}$ Compared to the United States, European fertility rates are lower, the population is considerably older, and there are fewer women of childbearing age. Thus, the immediate challenges European nations face in dealing with widespread natural decrease may provide important lessons to U.S. policy makers as they prepare to address this issue in the future.

\section{Data}

Birth and death data in this brief are from the National Center for Health Statistics (NCHS) of the Centers for Disease Control's WONDER database for each year between 1999 and $2014 .{ }^{25}$ Data on the percentage of elderly, the percentage of women of childbearing age, and the percentage of females who are less than 15 years of age are from the U.S. Census Bureau's Annual Estimates of the Resident Population by Sex, Age, Race, and Hispanic Origin for the United States and States for July $1,2014 .{ }^{26}$ The data used to compute the total fertility rate are derived from the 2014 American Community Survey public-use file.

The classification of births and deaths by race in the NCHS data used here differs from the procedures used by the Census Bureau. Thus, there are differences in the number of births and deaths classified in a specific category by race/ Hispanic origin between the two agencies. NCHS data do not allow for classification of multiple-race births or deaths-so all births are classified into one race category, that of the infant's mother; the race and Hispanic origin of the infant's father are not considered. In contrast, Census Bureau estimates allow inclusion of births and deaths of two or more races. NCHS data consistently show more non-Hispanic white births and fewer Hispanic births than Census data at the national level. Thus, our calculations likely underestimate white natural decrease compared to similar estimates using Census Bureau data. Only NCHS data are available for race/Hispanic origin of births and deaths for states.

\section{End not e s}

1. Kenneth M. Johnson, Layton M. Field, and Dudley L. Poston Jr., "More Deaths than Births: Subnational Natural Decrease in Europe and the United States," Population and Development Review 41, no. 4 (2015): 651-80.

2. U.S. Census Bureau, "2014 National Population Projections: Summary Tables (Table 9)" (Washington, DC: U.S. Census Bureau, 2015), accessed at http://www.census.gov/population/ projections/data/national/2014/ summarytables.html on July 22, 2016.

3. Kenneth M. Johnson and Daniel T. Lichter, "Diverging Demography: Hispanic and Non-Hispanic Contributions to U.S. Population Redistribution and Diversity," Population Research and Policy Review 35 (2016): 705-725; Rogelio Sáenz, "Latinos in the United States 2010," Population Reference Bureau Bulletin Update (Dec. 2010), accessed at http:// www.prb.org/pdf10/latinos-update2010. pdf on July 22, 2016; Rogelio Sáenz and Maria Cristina Morales, Latinos in the United States: Diversity and Change (Cambridge, UK: Polity Press, 2015).

4. Centers for Disease Control, "CDC WONDER Database: About Underlying
Cause of Death, 1999-2014" (Atlanta, GA: CDC, 2016a), accessed at http:// wonder.cdc.gov/ucd-icd10.html on July 1, 2016; Centers for Disease Control, "CDC WONDER Database: Live Births" (Atlanta, GA: CDC, 2016b), accessed at http://wonder.cdc.gov/natality.html on July 1, 2016.

5. Kenneth M. Johnson, "U.S. Births Remain Low as the Great Recession Wanes," National Fact Sheet \#34 (Durham, NH: Carsey School of Public Policy, 2016), accessed at https://carsey. unh.edu/publication/us-births-low on August 9, 2016; Gretchen Livingston, "In a Down Economy, Fewer Births" (Washington, DC: Pew Research Center Social \& Demographic Trends, 2011), accessed at http://www.pewsocialtrends. org/2011/10/12/in-a-down-economyfewer-births/ on July 28, 2016.

6. Johnson, Field, and Poston (2015).

7. Johnson, Field, and Poston (2015).

8. Johnson, Field, and Poston (2015).

9. U.S. Census Bureau, "Annual Estimates of the Resident Population by Sex, Age, Race, and Hispanic Origin for the United States and States: April 1, 2010 to July 1, 2014" (Washington, DC: U.S. Census Bureau, 2014a), accessed at http://factfinder.census. gov/faces/tableservices/jsf/pages/ productview.xhtml?pid=PEP_2015_ PEPASR6H\&prodType $=$ table on June 25, 2016.

10. U.S. Census Bureau (2014a).

11. The total fertility rate (TFR) represents the number of births that a woman would have if she went through her childbearing years (15 to 44 ) conforming to the current age-specific fertility rates. We use data from the 2014 American Community Survey (ACS) public-use file to compute the TFR. Because the ACS data contain information on whether or not a woman gave birth in the previous year rather than the number of births during that time, the TFR based on these data is likely to be slightly lower than that produced with birth-certificate data as 
the former does not take into account multiple births. Birthcertificate data are not available for non-Hispanic whites at the state level. Also see Steven Ruggles, Katie Genadek, Ronald Goeken, Josiah Grover, and Matthew Sobek, Integrated Public Use Microdata Series: Version 6.0 [Machine-readable database] (Minneapolis, MN: University of Minnesota, 2015), accessed at https://usa.ipums.org/usa/index.shtml on July 1, 2016.

12. U.S. Census Bureau (2014a).

13. Johnson, Field, and Poston (2015); Johnson and Lichter (2016).

14. Anne Case and Angus Deaton, "Rising Morbidity and Mortality in Midlife Among White Non-Hispanic Americans in the 21st Century," Proceedings of the National Academy of Sciences of the United States of America 112, no. 49 (2015): 1-6; S. M. Monnat and K. K. Rigg, "Examining Rural/Urban Differences in Prescription Opioid Misuse Among US Adolescents," Journal of Rural Health 32, no. 2 (2015): 204-18.

15. Centers for Disease Control (2016a).

16. U.S. Census Bureau, "2014 National Population Projections Tables (Table 10)" (Washington, DC: U.S. Census Bureau, 2014b), accessed at http://www.census.gov/population/ projections/data/national/2014.html on July 29, 2016.

17. Sáenz (2010); Sáenz and Morales (2015).

18. U.S. Census Bureau (2014a).

19. Rogelio Sáenz, "A Transformation of Mexican Migration to the United States," National Issue Brief \#186 (Durham, NH: Carsey School of Public Policy, 2015), accessed at http://scholars.unh.edu/carsey/247/ on July 29, 2016; Jeffrey S. Passel and Ana Gonzalez-Barrera, "Net Migration From Mexico Falls to Zero-and Perhaps Less" (Washington, DC: Pew Research Hispanic Trends Project, 2012), accessed at http://www.pewhispanic. org/2012/04/23/net-migration-from-mexico-falls-to-zeroand-perhaps-less/ on July 29, 2016.
20. Sáenz and Morales (2015); Mark Mather, “The Decline in U.S. Fertility" (Washington, DC: Population Reference Bureau, 2014), accessed at http://www.prb.org/Publications/ Datasheets/2014/2014-world-population-data-sheet/usfertility-decline-factsheet.aspx on July 29, 2016.

21. Centers for Disease Control (2016).

22. Johnson and Lichter (2016b).

23. Johnson, Field, and Poston (2015).

24. Johnson, Field, and Poston (2015).

25. Centers for Disease Control (2016a, 2016b).

26. U.S. Census Bureau (2014a).

\section{About the Authors}

Rogelio Sáenz is dean of the College of Public Policy and Mark G. Yudof Endowed Professor at the University of Texas at San Antonio. He is also a policy fellow of the Carsey School of Public Policy (rogelio. saenz@utsa.edu).

Kenneth M. Johnson is senior demographer at the Carsey School of Public Policy and professor of sociology at the University of New Hampshire and is an Andrew Carnegie Fellow (ken.johnson@unh.edu).

\section{A cknowledgments}

The authors thank Michele Dillon, Michael Ettlinger, and Laurel Lloyd at the Carsey School of Public Policy for their thoughtful suggestions, and Patrick Watson for his editorial assistance. Dr. Johnson's work on this project was supported in part by the New Hampshire Agricultural Experiment Station and his Andrew Carnegie Fellowship. The views expressed here are his and do not represent the official views of the Carnegie Corporation or the New Hampshire Agricultural Experiment Station.

\section{(NH University of New Hampshire Carsey School of Public Policy}

The Carsey School of Public Policy at the University of New Hampshire is nationally recognized for its research, policy education, and engagement. The school takes on the pressing issues of the twenty-first century, striving for innovative, responsive, and equitable solutions.

$$
\begin{aligned}
& \text { Huddleston Hall • } 73 \text { Main Street • Durham, NH o3824 } \\
& \text { (603) 862-2821 } \\
& \text { TTY UsERs: DIAL 7-1-1 OR 1-800-735-2964 (RELAY N.H.) }
\end{aligned}
$$

$$
\text { carsey.unh.edu }
$$

